\title{
Does Compact Urban Development Foster Environment Sustainability?
}

\author{
Yuan Li-Ke
}

\begin{abstract}
The idea of 'compact urban form' has been examined mainly in the context of developed countries, but rarely has it been studied in the case of Chinese cities. A compact city is a special urban form with inherent physical, social and institutional constraints on environmental issues that obstruct the achievement of sustainability. In this study, population density and GDP density is used as the index of compact city to investigate the impact on environmental sustainability in China. It argues that exists the spatial effect in the examination of the determinants of environment sustainability. There exists a U- shaped function on the relationship between population density and $\mathrm{SO}_{2}$ emission when considering the spatial effect. The statistical significant inverted $\mathrm{U}$-shaped curves are found in the estimation of the impact of GDP density on the pollution. It illustrates that city's pollution will be decreased with the compact urban development.
\end{abstract}

Index Terms-Compact city, environmental sustainability, urban development.

\section{INTRODUCTION}

Sustainable urban development entails integration of environmental interests into decision-making at the local level [1]. Recently, in connection with the planning of environment friendly cities, many urban planners have become aware of the 'compact city' concept. Newman and Kenworthy analyzed the relationship between population density and gasoline consumption, and clarified that low density leads to high gasoline consumption, and high density leads to low gasoline consumption [2]. After this seminal paper, many studies have discussed possible compact urban forms from the viewpoint of sustainable development [3]. However, the few studies examine the effect of externality in the analysis of determinants with a spatial econometric approach. This paper contributes to the literature is this way.

The paper is organized as follows. Section II reviews the relationship between compact city and environmental sustainable development. Section III examines a number of spatial econometric issues and the data source in this paper. Section IV adopts the spatial econometric approach to test the spatially adapted model at the China municipal cities level, and Section V concludes the paper.

\section{COMPACt City AND ENVIRONMENTAL SUSTAINABLY DEVELOPMENT}

It has been extensively argued that the conditions provided by the compact city and compact urban form are more

Manuscript received April 22, 2015; revised June 17, 2015.

Yuan Li-Ke is with the Chinese Academy of Science and Technology for Development, Beijing, 100038, China (e-mail: yuanlike@126.com). sustainable than sprawl [4]-[6]. The urban form of the compact city is generally supposed to promote environmental, social and global sustainability by increasing the density of the built-up area and residential population, intensifying urban economic, social and cultural activities and manipulating urban size, form, structure and settlement systems [7].

There is now a large body of literature explicitly relating urban forms to pollution emissions [8]-[10]. Many reports suggest that a compact city reduces energy, makes investments in public infrastructure more viable, reduces land usage thereby preserving agricultural land and natural areas, and is positively associated with social diversity and with cultural and economic development [11], [12]. Compactness, however, also entails the risk of deteriorating environmental and spatial quality [13] and of exposing large numbers of people to natural and industrial risks [1]. This has become known as the 'compact city dilemma' [14], [15]. Some of the main arguments opposed to the compact city are that the concept of the green city [16] is in contradiction to that of the compact city and that the compact city would cause congestion, with increased pollution, on the local scale [17]. The empirical example of Taiwan shows the density and the process of intensification not only positively influences economic sustainability but also negatively influence environmental and social sustainability [18].

However, there are inherent difficulties in finding an accurate definition of the 'compact city', and being able to analyze what is, and what is not, a compact urban form. Clearly, there is more to the 'compact city' model than just an increase in population density [19], but the GDP in metro areas [20]. What's more, most empirical tests fail to correctly understand the role of externality in the theories presented above. The current paper focuses on the effect of compact city on the environment sustainability. Additional effects that environment might have externality are examined.

\section{Methodological Approaches and Data Source}

The usual estimation equation in examination of environmental sustainability is given by

$$
Y=\beta X+\varepsilon
$$

where $Y$ is the dependent variable, and $X$ represents the explanatory variable. $\beta$ is the parameter of independent variable $X ; \varepsilon$ is known as the white noise disturbance item. In this paper, I consider the possibility that environment are spatially correlated. The primary concern is that environment is a district may be affected by environment in neighboring cities, i.e., there might be pollution spillovers. The spatial lag 
model in matrix form is given by

$$
Y=\beta X+\rho W Y+\varepsilon
$$

where $\rho$ is the spatial autocorrelation coefficient, $W$ is the spatial weight matrix. Hence, the majority of the literature refers to geographical weights. It is common to use geographical distances [21], or more precisely, to use great circle distances between regions' centroids [22]. But this contains the inherent assumption that knowledge spillover sources are located in the regions' centroids. Another way, which is also considered in this study, is simply to refer to a binary weighting scheme. If a region $i$ is a neighbor of another region $j$, then the $i$-th element of $W, W_{i j}$ takes 1 , otherwise 0 . In this specification, the parameter $\rho$ could be interpreted as a measure of spatial interaction across contiguous regions. In other words, the spatial lag model consents to quantify how the rate of growth in a region is affected by the one in its surrounding regions. $W Y$, the spatial lag dependent variable, is correlated with the disturbances, even when the latter are i.i.d. This can be seen form the reduced form of (3)

$$
Y=(I-\rho W)^{-1} \beta X+(I-\rho W)^{-1} \varepsilon
$$

Consequently, the spatial lag term must be treated as an endogenous variable and proper estimation methods must account for this endogeneity (OLS will be biased and inconsistent due to the simultaneity bias).

A spatial error model is a special case of a regression with a non-spherical error term, in which the off-diagonal elements of the covariance matrix express the structure of spatial dependence. The spatial error model is

$$
Y=\beta X+\varepsilon \text { and } \varepsilon=\lambda W \varepsilon+\mu
$$

Since $\varepsilon=(I-\lambda W)^{-1} \mu$, and thus $Y=\alpha+\beta X+(I-\lambda W)^{-1} \mu$, is equivalent to

$$
Y=\lambda W Y+\beta X-\lambda W \beta X+\varepsilon
$$

where $\lambda$ is the spatial autocorrelation coefficient for the error term and $\varepsilon$ is a mean zero error term. The coefficient $\lambda$ present in the spatial error model measures the degree of spatial autocorrelation between error terms of neighboring regions.

Spatial model is estimated by Maximum Likelihood procedure given that OLS estimators are not appropriate when a lagged value of the dependent variable is inserted among the explanatory variables. The application of decision rules based on different spatial autocorrelation tests helps us to choose the best specification we have to estimate among all available spatial regressions.

The Moran's I test adapted to the regression residuals is very powerful against all forms of spatial dependence but it does not allow discriminating between them [23]. In this purpose, we can use two Lagrange Multiplier tests [22] as well as their robust counterparts, which allow testing the presence of the two possible forms of autocorrelation: LM-LAG for an autoregressive spatial lag variable and LM-ERR for a spatial autocorrelation of errors. The two robust tests R-LMLAG and R-LMERR have a good power against their specific alternative. The decision rule suggested by Anselin and Florax [23] can then be used to decide which specification is the more appropriate. If LM-LAG is more significant than LM-ERR and R-LMLAG is significant but R-LMERR is not, then the spatial autoregressive model is an appropriate one. Conversely, if LM-ERR are more significant than LM-LAG and R-LMERR is significant but R- LMLAG is not, then the appropriate specification is the spatial error model.

All the Data were taken from the China City Statistical Yearbook 2010. The number of cities is 284 . Some cities are not chosen in this paper for the missing values.

The main dependent variables used in this paper are three pollutants: waste water emissions, $\mathrm{SO}_{2}$ emissions and soot emission. The three emissions are the main pollutions in China. As such, they clearly capture a measure of environmental degradation. Based on the previous research [20], I use population per $\mathrm{km}^{2}$ municipal district and Secondary and tertiary industry GDP per $\mathrm{km}^{2}$ municipal district as the proxies of compact city. Table I presents the variables included in the model, and report the descriptive statistics. In order to avoid sharp fluctuations of the data, the paper takes the logarithm form for all the variables.

TABLE I: SUMMARY STATISTICS

\begin{tabular}{llllll}
\hline \hline Variable & Definition & Mean & Min & Max & Max \\
\hline \multirow{2}{*}{ WATER } & $\begin{array}{l}\text { Industrial waste } \\
\text { discharged per 1,000 } \\
\text { population }\end{array}$ & 5.120 & 3.606 & 6.295 & 0.434 \\
& $\begin{array}{l}\text { Industrial SO } 2 \\
\text { emission per 1,000 }\end{array}$ & 2.058 & -0.677 & 3.276 & 0.490 \\
$\mathrm{SO}_{2}$ & $\begin{array}{l}\text { population } \\
\text { Industrial soot } \\
\text { emission per 1,000 }\end{array}$ & 1.549 & -0.237 & 2.984 & 0.476 \\
SOOT & $\begin{array}{l}\text { population } \\
\text { 1,000 population per }\end{array}$ & 2.281 & 1.124 & 4.059 & 0.442 \\
POP & $\begin{array}{l}\text { km municipal } \\
\text { district }\end{array}$ & & & & \\
DENSITY & $\begin{array}{l}\text { Secondary and } \\
\text { tertiary industry }\end{array}$ & 3.386 & 1.393 & 4.762 & 0.620 \\
GDP & $\begin{array}{l}\text { GDP per km } \\
\text { municipal district }\end{array}$ & & & & \\
DENSITY & & & & \\
\hline \hline
\end{tabular}

\section{EMPIRICAL ESTIMATION AND RESULTS}

Following Gert de Roo's contribution [14], the relationship between the compact city and the environmental is for more than one reason controversial. The compact urban development will mostly likely have a negative effect on the quality of the environmental. Refer to the Environmental Kuznets Curves; we posit a relationship between the logarithm of cities' emissions per capita, the logarithm of population and GDP density and their squared value. The estimation equation is given by

$$
\begin{gathered}
\log (E)= \\
\alpha_{1}+\beta_{1} \log (\text { compact city })+\beta_{2}[\log (\text { compact city })]^{2}+
\end{gathered}
$$

where $E$ is either log of per capita waste water, $\mathrm{SO}_{2}$ or soot emissions in cities, compact city is measured by either population or GDP per $\mathrm{km}^{2}$ municipal district. To allow for the $\mathrm{U}$ shaped curves, I include the log compact city and the 
square of the log of compact city.

It is well known that regional data cannot be regarded as independently generated because of the presence of spatial similarities among neighboring regions [23]. None growth of the country, neither economic nor environmental (sustainable) can exists without any impact of regions situated closely. Global spatial autocorrelation index Global Moran's I is the indicator to measure global spatial autocorrelation observation units. The Moran's I statistic for per capita waste water is 0.288 and the related p-value is 0.002 . Similarly, the Moran's I statistic for per capita $\mathrm{SO}_{2}$ and Soot is 0.215 and 0.285 ; both the related p-value are 0.002 . These statistics provide strong evidence of spatial autocorrelation is the dependent variable that I correct for by using that spatial econometric model.

Spatial econometrics recognizes that units might be correlated across space [22]. As indicated above, estimating a linear model with least squares in the presence of spatial correlation would yield biased estimates. The spatial lag model for compact urban development and environment sustainability is given by

$$
\begin{gathered}
\log (E)= \\
\alpha_{1}+\beta_{1} \log (\text { compact city })+\beta_{2}[\log (\text { compact city })]^{2}+ \\
\rho W \log (E)+\mu
\end{gathered}
$$

The variable gathered by the term $\mathrm{W} \log (E)$ is therefore the spatial lag for the pollution. We interpret an influence of this variable on the endogenous as evidence of intercity spillovers of the pollution. The second way to incorporate spatial autocorrelation into the model is to specify a spatial process for the disturbance term.

$$
\left\{\begin{array}{c}
\log (E)=\alpha_{1}+\beta_{1} \log (\text { compact city }) \\
+\beta_{2}[\log (\text { compact city })]^{2}+\mu \\
\mu=\lambda \mathrm{W} \mu+\varepsilon
\end{array}\right.
$$

The equation is estimated by OLS for each pollutant in turn and the results are presented in Table II. There appears to be no relationship between pollution emission and population density. Removing the statistically insignificant higher-order term for population density reveals a statistically significant compact city elasticity of 0.139 to the water pollution. The results illustrate that the increase of population density will consume more water and aggravate the water pollution, but no significant impact on $\mathrm{SO}_{2}$ and soot emissions. The coefficient of logarithm compact city square is not statistically significant except the last column. It shows that there is no curve relationship between the pollution and compact urban development (except the estimate in the last column) and the pollution does not been solved automatically with the development of compact city.

The elasticity of emissions with respect to economic index of compact city is positive and strongly significant. This illustrate that there are a monotonic relationship between compact city and waste water \& $\mathrm{SO}_{2}$ emissions per capita. The models that include a second-order effect for compact city indicate that, on average, there is evidence of an inverted-U relationship between Soot emissions and compact urban development. The turn point is 3.579 ; it means that from this level of compact urban development provides to decrease of soot emissions.

TABLE II (A): RESULTS OF OLS MODEL

\begin{tabular}{llll}
\hline \hline Independent & WATER & $\mathrm{SO}_{2}$ & SOOT \\
Variables & & & \\
\hline Constant & $4.365 * * *$ & $3.082^{* * * *}$ & $2.816^{* * *}$ \\
& $(0.686)$ & $(0.767)$ & $(0.759)$ \\
POP DENSITY & 0.412 & -0.720 & -0.855 \\
& $(0.505)$ & $(0.565)$ & $(0.558)$ \\
POP DENSITY & -0.050 & 0.124 & 0.141 \\
R-squared & $(0.092)$ & $(0.103)$ & $(0.102)$ \\
F-statistic & 0.019 & 0.007 & 0.013 \\
Log likelihood & $2.782 *$ & 0.964 & 1.858 \\
AIC & -163.143 & -195.183 & -191.919 \\
Moran's I & 332.287 & 396.365 & 389.838 \\
LM-lag & $7.253 * * *$ & $5.671 * * *$ & $7.523 * * *$ \\
Robust LM-lag & $14.031 * * *$ & $38.743 * * *$ & $52.005 * * *$ \\
LM-error & 1.168 & $10.253 * * *$ & $4.236 * *$ \\
Robust LM-error & $39.137 * * *$ & $29.690 * * *$ & $52.948 * * *$ \\
\hline \hline
\end{tabular}

TABLE II (B): RESULTS OF OLS MODEL

\begin{tabular}{llll}
\hline \hline Independent & WATER & SO2 & SOOT \\
Variables & & & \\
\hline Constant & $3.433 * * *$ & 0.641 & 0.043 \\
& $(0.536)$ & $(0.632)$ & $(0.635)$ \\
GDP DENSITY & $0.752 * *$ & $0.713 *$ & $0.866 * *$ \\
& $(0.332)$ & $(0.391)$ & $(0.393)$ \\
GDP DENSITY & -0.073 & -0.084 & $-0.121 * *$ \\
R-squared & $(0.050)$ & $(0.059)$ & $(0.060)$ \\
F-statistic & 0.155 & 0.048 & 0.024 \\
Log likelihood & $25.858^{* * *}$ & $7.138 * * *$ & $3.464 * *$ \\
AIC & -141.927 & -189.117 & -190.326 \\
Moran's I & 289.854 & 384.234 & 386.651 \\
LM-lag & $6.501 * * *$ & $6.164 * * *$ & $7.681 * * *$ \\
Robust LM-lag & $12.473 * * *$ & $37.338 * * *$ & $50.349 * * *$ \\
LM-error & 1.830 & $6.352 * *$ & 2.686 \\
Robust LM-error & $39.315 * * *$ & $35.252 * * *$ & $55.268 * * *$ \\
\hline \hline Notes: Observations 284 regions; Robust standard errors are given in \\
parentheses; * significant at the 10\% level; **significant at the 5\% level; \\
$* * *$ significant at the 1\% level & & \\
& & & \\
\hline
\end{tabular}

The results from the liner regression models represent the estimated average or global relationship between pollution and compact urban development in China. However, the values of the Moran's I statistic and its associated z-score show that, in all models, the null hypothesis that the residuals are not spatially correlated can be rejected at the one percent level in favor of the hypothesis that the residuals exhibit spatial correlation.

I now perform a variety of tests in order to determine whether spatial relationships are present in the regressions and if so what form they take. Two tests are employed, namely, the LM test and the Robust LM test, which differ in that the latter is valid if spatial autocorrelation is present but not controlled for. In Tables III, there are results of spatial estimation of the model for china's cities, conducting that compact urban development has influences that environmental quality but including spatial dependence as a meaningful aspect in regional analysis. Basically, the values of R square and Log likelihood test in the spatial econometric model are greater meanwhile; the values of AIC (Akaike info criterion) are less than those estimated by the classical regression model. These could well prove that the spatial model is the optimal model to study the spatial dependence of 
pollution. Location and distance are important forces of spatial spillovers of air pollutions, the coefficients on the spatial lag and spatial error terms are highly significant. In $\mathrm{SO}_{2}$ spatial lag model the spatial lag term of $\mathrm{WlogSO}_{2}$ reflects the spatial dependence inherent in the sample data, measuring the average influence on observations by their neighboring observations. In Water and Soot spatial error model, the coefficient on the spatially correlated errors Lambda is added as an additional indicator. It has a positive effect.

TABLE III (A): RESULtS OF SPATIAL ECONOMETRIC MODEL

\begin{tabular}{llll}
\hline \hline $\begin{array}{l}\text { Independent } \\
\text { Variables }\end{array}$ & WATER & $\mathrm{SO}_{2}$ & SOOT \\
\hline Constant & $4.672 * * *$ & $2.484^{* * *}$ & $2.599^{* * * *}$ \\
& $(0.658)$ & $(0.708)$ & $(0.731)$ \\
POP DENSITY & 0.213 & $-0.988^{*}$ & -0.664 \\
& $(0.478)$ & $(0.516)$ & $(0.531)$ \\
& POP DENSITY & \\
& -0.019 & $0.172^{*}$ & 0.098 \\
$\rho$ & $(0.087)$ & $(0.094)$ & $(0.096)$ \\
& & $0.478^{* * *}$ & \\
$\lambda$ & & $(0.054)$ & \\
& $0.662 * * *$ & & $0.631^{* * *}$ \\
R-squared & $(0.051)$ & & $(0.054)$ \\
Log likelihood & 0.216 & 0.163 & 0.204 \\
AIC & -138.243 & -174.052 & -167.483 \\
Likelihood ratio & 282.486 & 356.104 & 340.965 \\
test & $49.801^{* * *}$ & $42.261^{* * *}$ & $48.873^{* * *}$ \\
\hline \hline
\end{tabular}

TABLE III (B): RESULTS OF SPATIAL ECONOMETRIC MODEL

\begin{tabular}{llll}
\hline \hline $\begin{array}{l}\text { Independent } \\
\text { Variables }\end{array}$ & WATER & SO2 & SOOT \\
\hline Constant & $2.568^{* * *}$ & -0.417 & -0.661 \\
& $(0.536)$ & $(0.583)$ & $(0.626)$ \\
GDP DENSITY & $1.317 * * *$ & $0.821^{* *}$ & $1.283^{* * *}$ \\
& $(0.323)$ & $(0.359)$ & $(0.379)$ \\
GDP DENSITY & \\
& $-0.162 * * *$ & $-0.104 *$ & $-0.183 * * *$ \\
$\rho$ & $(0.048)$ & $(0.055)$ & $(0.057)$ \\
& & $0.461 * * *$ & \\
$\lambda$ & & $(0.054)$ & $0.664 * * *$ \\
& $0.677 * * *$ & & $(0.051)$ \\
R-squared & $(0.050)$ & & 0.228 \\
Log likelihood & 0.314 & 0.193 & -163.897 \\
AIC & -119.360 & -168.734 & 344.762 \\
Likelihood ratio & 244.721 & 345.469 & $52.857 * * *$ \\
test & $45.134 * * *$ & $40.764 * * *$ \\
\hline \hline
\end{tabular}

Considering the spatial effect, there exists a U-shaped function of the relationship between $\mathrm{SO}_{2}$ pollution and population index of compact city. It shows there is an optimal point of population density of the city to minimize the pollution. It confirms that increasing residential density is an important tenet of compact urban development in theory and policy but can be a contentious issue in practice [24]. It is also clear that the environmental impact indicator is an inverted U-shaped function between pollution and economic index of compact city. The turning point of compact city for waste water emission, $\mathrm{SO}_{2}$ emission and soot emission is $4.065,3.947$ and 3.505 (logarithm value) respectively. It means that from these levels of compact city, the environment degradation decrease. Many cities in China have beyond the turn point. It illustrate that the relationship between the pollution and compact urban development of these cities is on the stage of benign circulation. Taking Shanghai as an example, the logarithm economic index of compact city is 4.515 , so the point elasticity of compact urban development to Waste water pollution is 0.586. It illustrate that the ratio of compact city increase $1 \%$, the pollution will decrease $0.586 \%$. The findings support the compact city claim that economic activities can be provided and designed in dense urban areas, but different approach in different stages of development. To some extent, it indicates that physical planning and policy decisions are more important than density [4].

\section{CONCLUSION}

The main purpose of this paper has been to highlight the relationship between compact urban development and environmental sustainability. Results obtained are made robust to possible spatial dependence or correlation across observations through the use of spatial econometrics tools. After having detected the presence of spatial effects in the model, the study find there are a U-shaped curve of the impact of population density on the $\mathrm{SO}_{2}$ emission Government sector should control the population size in the limited municipal area. Excess population density of the city has a negative effect on the environment sustainability. For the economic index of compact city, there exists a statistical significant inverted U-shaped function. It implies the cities' environment sustainability will be improved gradually with the economic development of compact city.

\section{REFERENCES}

[1] R. Stigt, P. P. J. Driessen, and T. J. M. Spit, "Compact city development and the challenge of environmental policy integration: A multi-level governance perspective," Environmental Policy and Governance, vol. 23, pp. 221-233, Aug. 2013.

[2] P. Newman and J. Kenworthy, Sustainability and Cities: Overcoming Automobile Dependence, Washington, DC: Island Press, 1999.

[3] K. Nakamichi, M. Taniguchi, and R. Matsunaka, "A time series analysis of relationship between urban layout and automobile reliance has cities shifted to integrate land use and transport?" Urban Transport $X I V$, Southampton: WIT Press, 2008, pp. 415-24.

[4] S. Dave, "High urban densities in developing countries: A sustainable solution?" Built Environment, vol. 36, no. 1, pp. 9-27, Mar. 2010.

[5] N. Ferguson and L. Woods, "Travel and mobility," Dimensions of the Sustainable City, London, UK: Springer, 2010, pp. 53-74.

[6] M. Lindsay, K. Williams, and C. Dair, "Is there room for privacy in the compact city?" Built Environment, vol. 36, no. 1, pp. 28-36, Mar. 2010.

[7] R. Burgress, "The potential of the compact city for promoting social equity," Achieving Sustainable Urban Form, London, UK: E \& FN Spon, 2000, pp. 19-29.

[8] P. C. Manins, M. E. Cope, P. J. Hurley, P. W. Newton, N. C. Smith, and L. Q. Marquez, "The impact of urban development on air quality and energy use," in Proc. the $14^{\text {th }}$ International Clean Air and Environment Conference, Melbourne, Mitcham, VIC, Clean Air Society of Australia and New Zealand, pp. 331-336, 1998.

[9] T. J. Dolney, "Using simulation to estimate vehicle emission in response to urban sprawl within Geaua county, Ohio," Ohio Journal of Science, vol. 109, pp. 52-56, 2009.

[10] M. Schindler and G. Caruso, "Urban compactness and the trade-off between air pollution emission and exposure: Lessons from a spatially explicit theoretical model," Computer, Environment and Urban Systems, vol. 45, pp. 13-23, 2014.

[11] T. Elkin, D. McLaren, and M. Hillman, Reviving the City: Towards Sustainable Urban Development, Friends of the Earth, London, 1991.

[12] European Commission, Directorate General for Regional Policy, Cities of Tomorrow - Challenges, Visions, Ways Forward, Luxembourg: Publications Office of the European Union, 2011. 
[13] L. B. Janssen-Jansen, "Beyond sprawl: Principles for achieving more qualitative spatial development," DISP-The Planning Review, vol. 41 , pp. 36-41, 2005.

[14] G. de Roo, "Environmental planning and the compact city: A Dutch perspective," Studies in Environmental Science, vol. 72, pp. 1027-1042, 1998.

[15] N. Dempsey, "Quality of the build environment in urban neighborhoods," Planning Practice and Research, vol. 23, pp. 249-264, 2008.

[16] Commission of the European Communities (CEC), Green Paper on the Urban Environment, Brussels, European Commission, 1990.

[17] C. Knights, "Economic and social issues," The Compact City: A Sustainable Urban Form, London: E\&FN Spon, 1996.

[18] J. J. Lin and A. T. Yang, "Does the compact city paradigm foster sustainability? An empirical study in Taiwan," Environment and Planning B: Planning and Design, vol. 33, pp. 365-380, 2006.

[19] E. Burton, "Measuring urban compactness in UK towns and cities," Environment and Planning B: Planning and Design, vol. 29, pp. 219-250, 2002

[20] T. Matsumoto. (2012). Compact city policies: A comparative assessment applying a new definition of "urban". [Online]. Available: http://www.regionalstudies.org/uploads/conferences/presentations/eur opean- conference-2012/tadashi-matsumoto.ppt
[21] W. Keller, "Geographic localization of international technology diffusion," American Economic Review, vol. 92, pp. 120-142, Mar. 2002.

[22] L. Anselin, Spatial Econometrics: Methods and Models, Dordrecht, 1988.

[23] L. Anselin and R. J. G. M. Florax, "New directions in spatial econometrics: Introduction," Advances in Spatial Science, Berlin, Springer, 1995, pp. 3-16.

[24] M. Jenks and C. Jones, Dimensions of the Sustainable City, London: Springe, 2010.

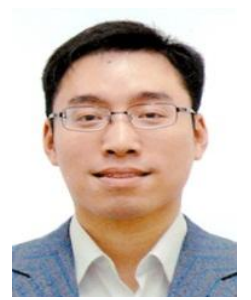

Yuan Li-Ke was born in Zhejiang province of China. He got the Ph.D degree in technical economics and management from Chongqing University in China.

$\mathrm{He}$ is now an associate professor of Chinese Academy of Science and Technology for Development. Dr. Yuan's research interests include technology foresight and assessment, technological innovation management and environmenta economics. 